\title{
An update on the role of bronchoscopy in the diagnosis of pulmonary disease
}

\author{
June Hong Ahn
}

Department of Internal Medicine, Yeungnam University College of Medicine, Daegu, Korea

Received: July 11, 2020

Revised: August 7, 2020

Accepted: August 8, 2020

Corresponding author:

June Hong Ahn

Department of Internal Medicine,

Yeungnam University College of

Medicine, 170 Hyeonchung-ro,

Nam-gu, Daegu 42415, Korea

Tel: +82-53-640-6577

Fax: +82-53-620-3849

E-mail: fireajh@gmail.com
Bronchoscopy has evolved over the past few decades and has been used by respiratory physicians to diagnose various airway and lung diseases. With the popularization of medical check-ups and growing interest in health, early diagnosis of lung diseases is essential. With the development of endobronchial ultrasound, ultrathin bronchoscopy, and electromagnetic navigational bronchoscopy, bronchoscopy has been able to widen its scope in diagnosing pulmonary diseases. In this review, we have described the brief history, role, and complications of bronchoscopy used in diagnosing pulmonary lesions, from simple flexible bronchoscopy to bronchoscopy combined with several up-to-date technologies.

Keywords: Bronchoscopy; Cryobiopsy; Electromagnetic navigation bronchoscopy; Endobronchial ultrasound; Lung diseases

\section{Introduction}

Since the introduction of the flexible fiberoptic bronchoscope in 1968, it has been used as an essential tool for diagnosing lung lesions [1]. Over the past decade or so, endobronchial ultrasound (EBUS) has been widely used clinically. Convex probe EBUS (CPEBUS) has replaced surgical mediastinal staging for lung cancer and is extensively used in diagnosing many central lung lesions [2]. Although the diagnostic yield of bronchoscopy is reasonable, CPEBUS provides a reliable diagnosis in patients with suspected lung cancer [3]. Radial probe EBUS (RP-EBUS), along with biopsy techniques using guide sheath (GS), is widely used to diagnose peripheral pulmonary lesions [4]. Although RP-EBUS guided transbronchial lung biopsy (TBLB) showed relatively lower diagnostic yield than computed tomography $(\mathrm{CT})$-guided transthoracic needle biopsy (TTNB) in diagnosing peripheral pulmonary lesions, the procedural risks were lower [5]. Recently, ultrathin bronchoscopy (UTB), electromagnetic navigational bronchoscopy (ENB), and cryobiopsy have been introduced to help diagnose lung diseas- es accurately. In this review, we have described the role of bronchoscopy in diagnosing pulmonary lesions.

\section{Flexible bronchoscopy}

Since Shigeto Ikeda first introduced the flexible fiberoptic bronchoscope in 1968, it has become an essential diagnostic tool for pulmonologists [1]. Many diagnostic procedures can be performed using flexible bronchoscopy (FB), such as airway inspection, bronchoalveolar lavage (BAL), bronchial brushing, endobronchial biopsy, TBLB, and conventional transbronchial needle aspiration (TBNA).

A thorough review of chest $\mathrm{CT}$ anatomy determining the lesion to obtain the sample should be done before conducting bronchoscopy. The most common indications for diagnostic FB are as follows: diagnosing airway injury or the presence of a foreign body, lung cancer, interstitial lung disease, pulmonary infection, and the investigation of hemoptysis $[6,7]$. Bronchoscopic findings of foreign body, bronchogenic carcinoma, and endobronchial tubercu-

Copyright (C) 2020 Yeungnam University College of Medicine

This is an Open Access article distributed under the terms of the Creative Commons Attribution Non-Commercial License (http://creativecommons.org/licenses/by-nc/4.0/) which permits unrestricted non-commercial use, distribution, and reproduction in any medium, provided the original work is properly cited. 
losis are shown in Fig. 1.

FB has diagnostic value in patients with airway injury. Concerning inhalation injury, FB is of great value in diagnosing and treating it and can be used to predict late structural complications, such as vocal cord stenosis and tracheal stenosis [8-10]. Early recognition of airway injury followed by early surgical interventions is associated with a favorable outcome in patients with acute tracheobronchial injuries by blunt or penetrating trauma [11]. In such cases, rapid diagnosis using FB is very important, and bronchoscopy is the procedure of choice.

FB is suggested as the first-line diagnostic tool in adult patients with foreign body aspiration into the lower airway [12]. The removal of a foreign body by FB was first reported in the 1970s. Since then, several studies reported the removal of foreign bodies with FB. The success rate of foreign body removal by $\mathrm{FB}$ is $61 \%$ to $97 \%$ [13].

FB is frequently used in diagnosing lung cancer. The diagnostic yield of bronchoscopy differs depending on the location of the lesion (central or peripheral). Concerning central lesions, the sensitivity of endobronchial forceps biopsy of a visible endobronchial lesion is $74 \%$. A minimum of three to five biopsy specimens is recommended to increase the rate of diagnosis in an endobronchial biopsy. The sensitivity of FB in diagnosing a central tumor increases to $88 \%$ with the addition of bronchial washing, brushing, endobronchial needle aspiration, and TBNA $[14,15]$. In the American
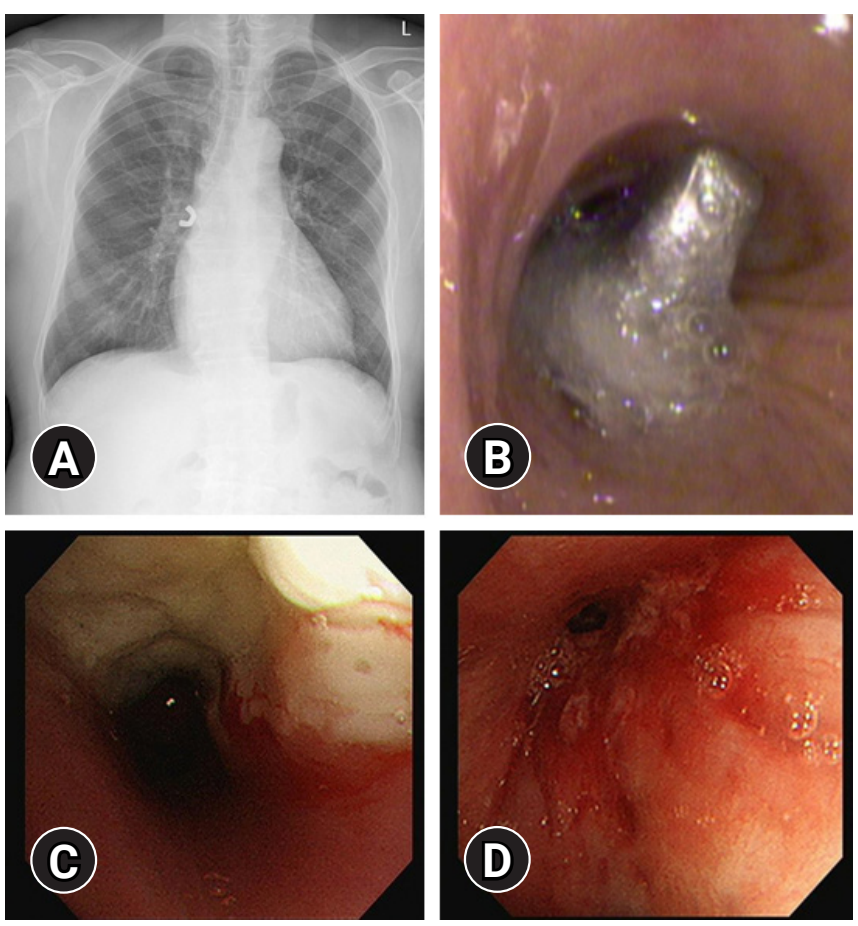

Fig. 1. Radiographic and bronchoscopic findings of foreign body $(A, B)$, bronchogenic carcinoma $(C)$, and endobronchial tuberculosis (D).
College of Chest Physicians' guidelines for establishing the diagnosis of lung cancer, the sensitivity of FB procedures in diagnosing peripheral tumors $(78 \%)$ was lower than that of central tumors (88\%) [14]. A minimum of six biopsy specimens is recommended to increase the rate of diagnosis in TBLB.

Since Andersen and Fontana [16] reported 450 cases undergoing TBLB in diffuse pulmonary lung disease (DPLD) in 1972, BAL and TBLB with FB are widely used in clinical practice for diagnosing DPLD. Eosinophilia and lymphocytosis with elevated CD4/CD8 ratio in BAL fluid help diagnose eosinophilic pneumonia and sarcoidosis, respectively [17]. TBLB helps diagnose sarcoidosis, eosinophilic pneumonia, hypersensitivity pneumonitis, cryptogenic organizing pneumonia, lymphangioleiomyomatosis, lymphangitic carcinomatosis, pulmonary Langerhans cell histiocytosis, and multiple lung infections [18].

In a patient with hemoptysis, it is essential to detect its cause and location. By far, studies have shown that CT is superior to FB for detecting the cause and location of hemoptysis [19-21]. However, $\mathrm{FB}$ can be a useful tool for performing an endoscopic treatment using cold saline, vasoconstrictive agents, topical hemostatic agents, and argon plasma coagulation. Pulmonary isolation technique using FB can also prevent blood aspiration from the bleeding lung to the intact lung, thereby securing the patients' airway and maintaining oxygenation [22].

FB can be performed safely, and most FBs are performed on an outpatient basis. A large retrospective cohort study demonstrated that the frequency of major (pneumothorax, pulmonary hemorrhage, and respiratory failure) and minor complications (laryngospasm, vomiting, vasovagal syncope, epistaxis, and bronchospasm) was $0.5 \%$ and $0.8 \%$, respectively [23]. A multicenter study conducted in Italy also showed that bronchoscopy is a safe method with a low incidence of complications (1.08\%) and mortality $(0.02 \%)$ [24].

These days, with the development of new technologies, such as EBUS, UTB, and ENB, combining FB with these new technologies much improved the diagnostic yield.

\section{Endobronchial ultrasound-transbronchial needle aspiration}

CP-EBUS is integrated with a convex-shaped ultrasonic transducer at the tip of the bronchoscope. The physician can observe the airway walls and surrounding structures by placing the end of the bronchoscope directly against the airway wall or by inflating the balloon with saline solution. It can be observed in real-time that the needle passes through the bronchial wall and the lesion of interest. The physician aspirates the tissue through a needle and uses 
it for pathological diagnosis. It is possible to avoid blood vessels through the power Doppler mode installed with ultrasound [25].

Yasufuku et al. [26] first reported experiences of CP-EBUSTBNA for sampling mediastinal and hilar lymph nodes in 2004. In the study, the sensitivity, specificity, and accuracy of $\mathrm{CP}$ EBUS-TBNA in diagnosing malignant lymph nodes were $95.7 \%$, $100 \%$, and $97.1 \%$, respectively. The procedure was safe, and there were no complications. Since then, with the experience of respiratory physicians, it is now widely used as a diagnostic tool for mediastinal nodal staging of lung cancer, central lung masses, lymphoma, sarcoidosis, and tuberculosis. CP-EBUS-TBNA for the mediastinal lymph node and the central lung mass is shown in Fig. 2.

In patients with suspected mediastinal lymph node involvement (lymph node enlargement, or positron emission tomography uptake), EBUS-TBNA is recommended as the best primary diagnostic tool over surgical staging. The overall median sensitivity, specificity, positive predictive value (PPV), and negative predictive value (NPV) were $89 \%, 100 \%, 100 \%$, and $91 \%$, respectively. Combined with endoscopic ultrasound (EUS)-needle aspiration, the pooled median sensitivity, specificity, PPV, and NPV were 91\%, $100 \%, 100 \%$, and $96 \%$, respectively [2]. The combination of EUS with bronchoscope-guided fine needle aspiration (EUS-B-FNA) and EBUS-TBNA provided additional diagnostic benefits through the sampling of inaccessible lesions by EBUS-TBNA, or when bronchoscopy was difficult due to dyspnea, or cough $[27,28]$. The
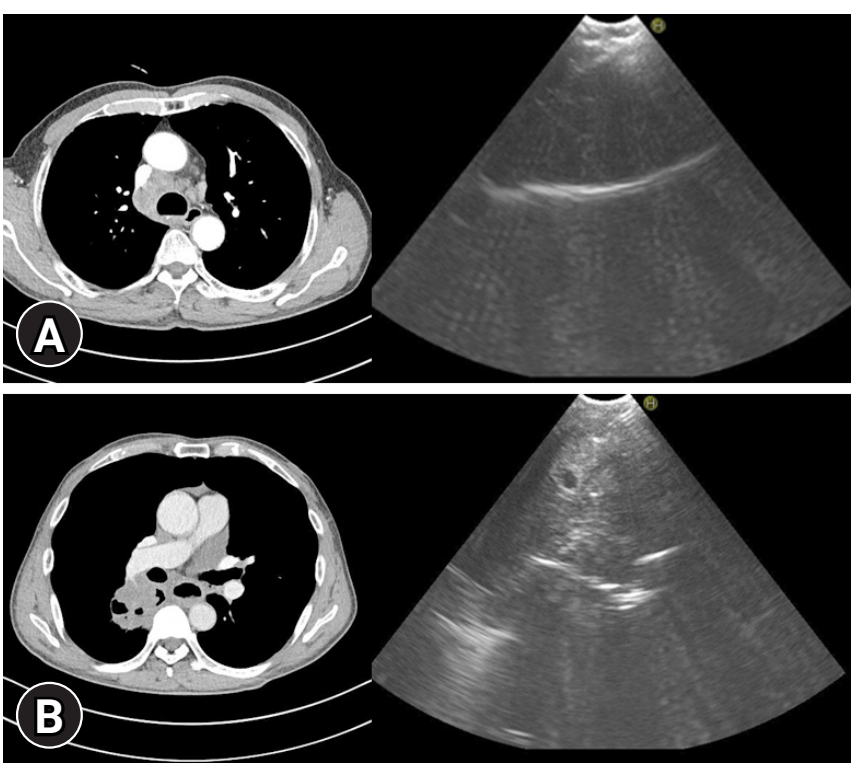

Fig. 2. Axial images of chest computed tomography and convex probe-endobronchial ultrasound-transbronchial needle aspiraton for the right paratracheal lymph node $(A)$ and the central lung mass (B). feasibility of molecular profiling using EBUS-TBNA derived samples were acceptable, and EBUS-TBNA provided a higher amount of RNA-extraction than bronchoscopy or CT-guided core biopsy $[29,30]$. Rebiopsy by EBUS-TBNA was also a useful sampling method for the analysis of acquired resistance to epidermal growth factor receptor-tyrosine kinase inhibitor $[31,32]$. In the absence of rapid on-site evaluation, at least three needle aspirations are recommended per lymph node station, in patients with suspected lung cancer for mediastinal staging [33,34].

Most central lung tumors can be diagnosed by FB; however, some central tumors are not easily diagnosed because they are not observed by FB. If a central tumor is not accessible by FB and is in contact with the bronchus, a direct tissue examination can be carried out using CP-EBUS-TBNA. In previous studies, the sensitivity of EBUS-TBNA for diagnosing unknown lung lesions was $82 \%$ to $94 \%$, in patients with central lung tumors not visible during FB. EBUS-related complications in diagnosing central tumors occurred in 5.4\% of the cases [35-37]. However, when it comes to diagnosing lymphoma, EBUS-TBNA reported an overall sensitivity of $66.2 \%$. Results showed a higher diagnostic sensitivity in diagnosing the recurrence of lymphoma (77.8\%), than the new diagnosis of lymphoma (67.1\%) [38].

In a meta-analysis of 553 patients with sarcoidosis, the pooled diagnostic accuracy of EBUS-TBNA for diagnosing sarcoidosis was 79\% [39]. EBUS-TBNA was also an effective diagnostic tool for intrathoracic tuberculosis. The pooled sensitivity of EBUS-TBNA for diagnosing intrathoracic tuberculosis lymphadenopathy was $87 \%$ [40].

Complication rates in EBUS-TBNA were low (1\% to 5\%) $[41,42]$. Rarely, serious complications such as bronchogenic cyst infection, mediastinal abscess, mediastinitis, pericarditis, and sepsis have been reported $[41,43]$.

\section{Endobronchial ultrasound and a guide sheath}

Using RP-EBUS, physicians can detect peripheral pulmonary lesions and can perform a biopsy. After peripheral pulmonary lesions are searched using an RP-EBUS inside GS, the RP is withdrawn, leaving the GS in place. Then bronchial brush and biopsy forceps are introduced into the GS, and brushings and biopsy specimens are collected [4].

In 1992, Hurter and Hanrath [44] reported the initial experience of RP-EBUS during routine FB. Following this, Kurimoto et al. [4] reported a technique using EBUS and a GS (EBUS-GS) to increase the diagnostic yield of peripheral pulmonary lesions. The overall yield of EBUS-GS was 77\%, 81\% for malignant lesions, and 
$69 \%$ for benign lesions.

Three classes of lesions were identified by RP-EBUS based on the internal structure of the lesion: type I (homogeneous pattern), type II (hyperechoic dots and linear arcs pattern), and type III (heterogeneous pattern). This endobronchial ultrasonographic information suggests the histology of the lung lesions [45].

A meta-analysis revealed that RP-EBUS had a point specificity of 1.00 (95\% confidence interval [CI], 0.99-1.00) and a point sensitivity of 0.73 (95\% CI, 0.70-0.76) for the detection of lung cancer. The diagnostic yield was higher for lesions $>20 \mathrm{~mm}$ (77.7\%; 95\% CI, 73\%-82\%) than for the lesions $\leq 20 \mathrm{~mm}$ (56.3\%; 95\% CI, 51\%-61\%). The diagnostic yield was also affected by the probe location. The ultrasound image associated with the probe location of RP-EBUS is shown in Fig. 3. Advancing the probe within the pulmonary lesions yielded the highest diagnostic accuracy (87\%). The yield when the probe was advanced adjacent to the lesion was lower (42\%) [46]. Several studies demonstrated that the probe position within the lesion was associated with diagnostic success in patients with EBUS-GS [47-49]. Besides this, peripheral location, bronchus sign on chest tomography, and the use of forceps as the first instrument were the independent factors for diagnostic success [49-52]. The cumulative diagnostic yield reached a plateau after the fifth biopsy specimen was collected. Thus, at least five biopsy specimens are needed to increase the diagnostic yield [49].

Izumo et al. [53] reported that RP-EBUS-GS could be considered as a diagnostic method for ground-glass opacity (GGO) lesions under the guidance of fluoroscopy. The diagnostic yield was $65 \%$, and a visible EBUS image was an independent factor affecting the diagnostic yield. The blizzard and mixed blizzard signs are useful ultrasound images to detect the correct location of GGO pulmonary lesions [54]. In our institution, RP-EBUSGS is performed to diagnose GGO pulmonary lesions (Fig. 4). In addition to diagnosing malignant lesions, RP-EBUS-GS was a useful and safe diagnostic method for diagnosing diffuse lung lesions [55].

The complication rates were lower ( $0 \%$ to $7.4 \%$ ) than CT-guided TTNB [56-58]. Pneumothorax occurred in $1.0 \%$ of the patients [59], and bleeding, infection, and breaking of radial probes can occur in some cases [58].
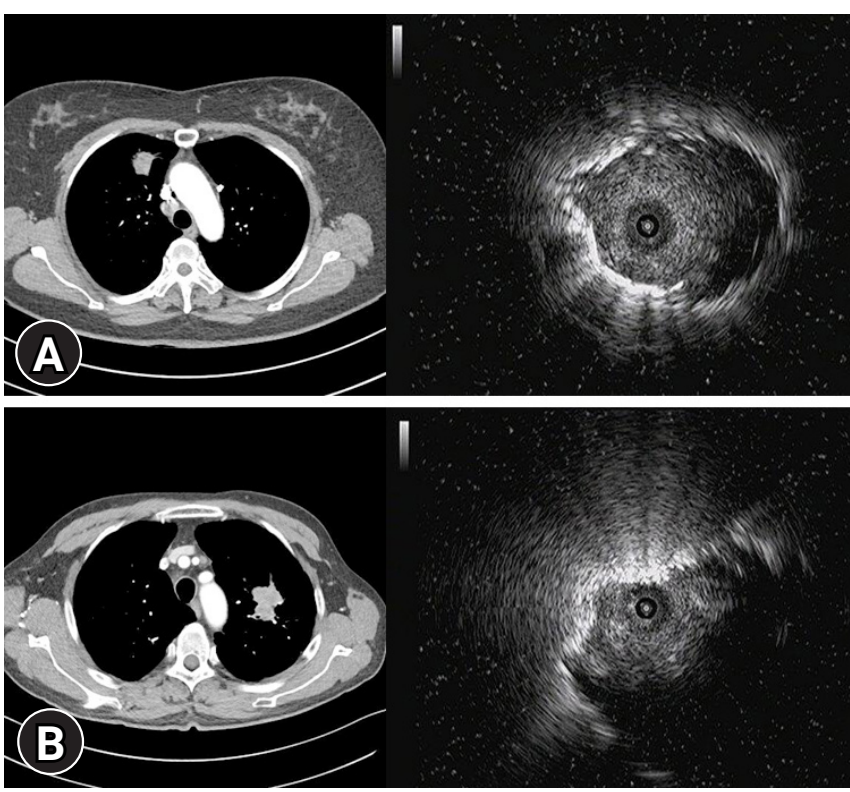

Fig. 3. Axial images of chest computed tomography and the ultrasound images associated with the probe location of radial probe-endobronchial ultrasound. (A) Within the lesion. (B) Adjacent to the lesion.
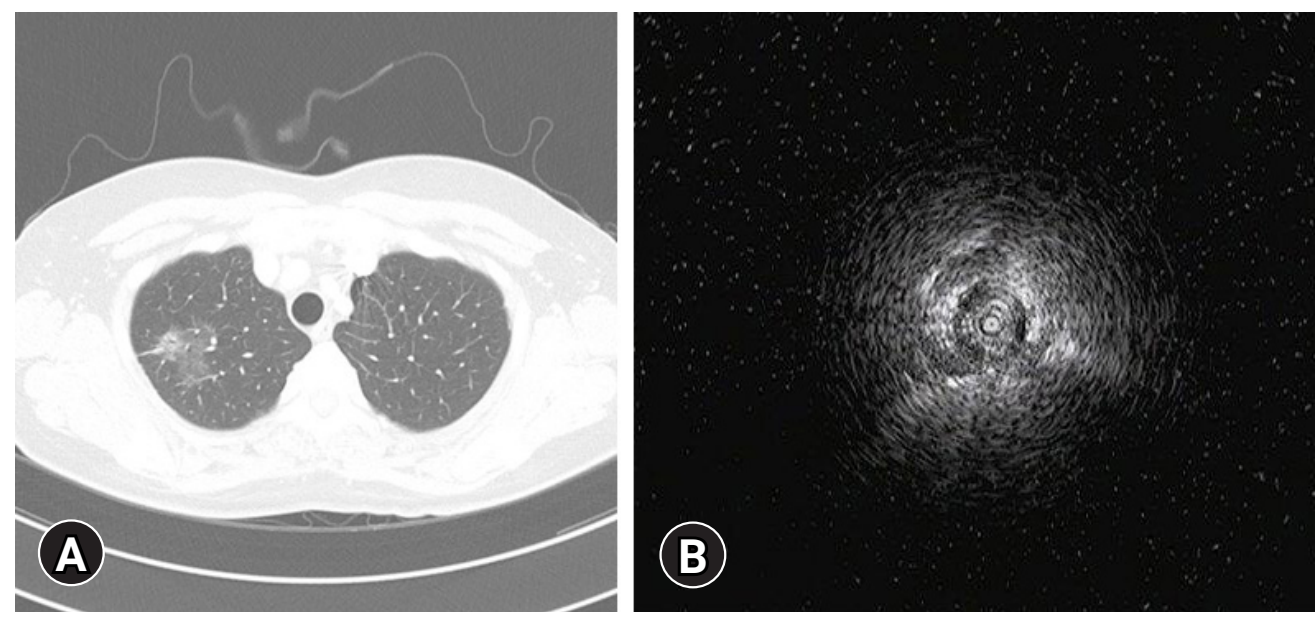

Fig. 4. Axial image of chest computed tomography $(A)$ and the ultrasound image $(B)$ associated with radial probe-endobronchial ultrasound-guide sheath performed to diagnose ground-glass opacity pulmonary lesions. 


\section{Ultrathin bronchoscopy}

According to previous studies, a bronchoscope with an external diameter of $3.0 \mathrm{~mm}$ is considered as a UTB [60]. An ultrathin fiberscope with an external diameter of $2.7 \mathrm{~mm}$ and an internal diameter of $0.8 \mathrm{~mm}$ with a working channel was introduced in 1996 . The ultrathin fiberscope was specifically used in a bronchoscope during mechanical ventilation through tracheal tubes in infants, suctioning, drug injection, and BAL [61]. The diagnostic rate of peripheral lung lesions using UTB was $60.0 \%$ to $69.4 \%$, and the diagnostic yield was $57 \%$ in lesions less than $20 \mathrm{~mm}[62,63]$. In a multicenter randomized trial conducted in Japan, the UTB with RP-EBUS group showed a superior diagnostic yield than the RP-EBUS-GS with a thin bronchoscopy group ( $74 \%$ vs. $59 \%, p=0.044$ ). Complications, such as pneumothorax, bleeding, and pneumonia was similar between the two groups ( $3 \%$ vs. $5 \%, p=0.595$ ) [64].

\section{Electromagnetic navigational bronchoscopy}

Despite the introduction of RP-EBUS, many peripheral pulmo- nary lesions are still difficult to diagnose. ENB systems were developed to overcome such limitations. Schwarz et al. [65] first reported ENB in diagnosing peripheral pulmonary lesions with an acceptable diagnostic yield (69\%) and safety.

An ENB works like a car reaching its destination via the global positioning system. By far, there are two ENB systems: the SuperDimension Navigation System (Medtronic, Minneapolis, MN, USA) and the SPiN System (Veran Medical Technologies, St. Louis, MO, USA) [66]. Fig. 5 shows the ENB assisted tissue sampling for a peripheral pulmonary lesion using the SPiN System.

In a meta-analysis of the diagnostic yield of ENB for lung nodules, the pooled sensitivity, specificity, and the diagnostic odds ratio were $82 \%, 100 \%$, and $97.62 \%$, respectively [67]. One-year results of the prospective, multicenter NAVIGATE study [68] revealed that diagnostic yield was $73 \%$. Greater nodule size, nodule visualization with RP-EBUS, presence of bronchus sign, lower registration error, and catheter suction technique were associated with an increased diagnostic yield. However, lower lobe location was correlated with a decreased diagnostic yield [67]. When ENB was combined with EBUS, the diagnostic yield was greater than ENB alone $(88 \%$ vs. $59 \%, p=0.02)[69]$.
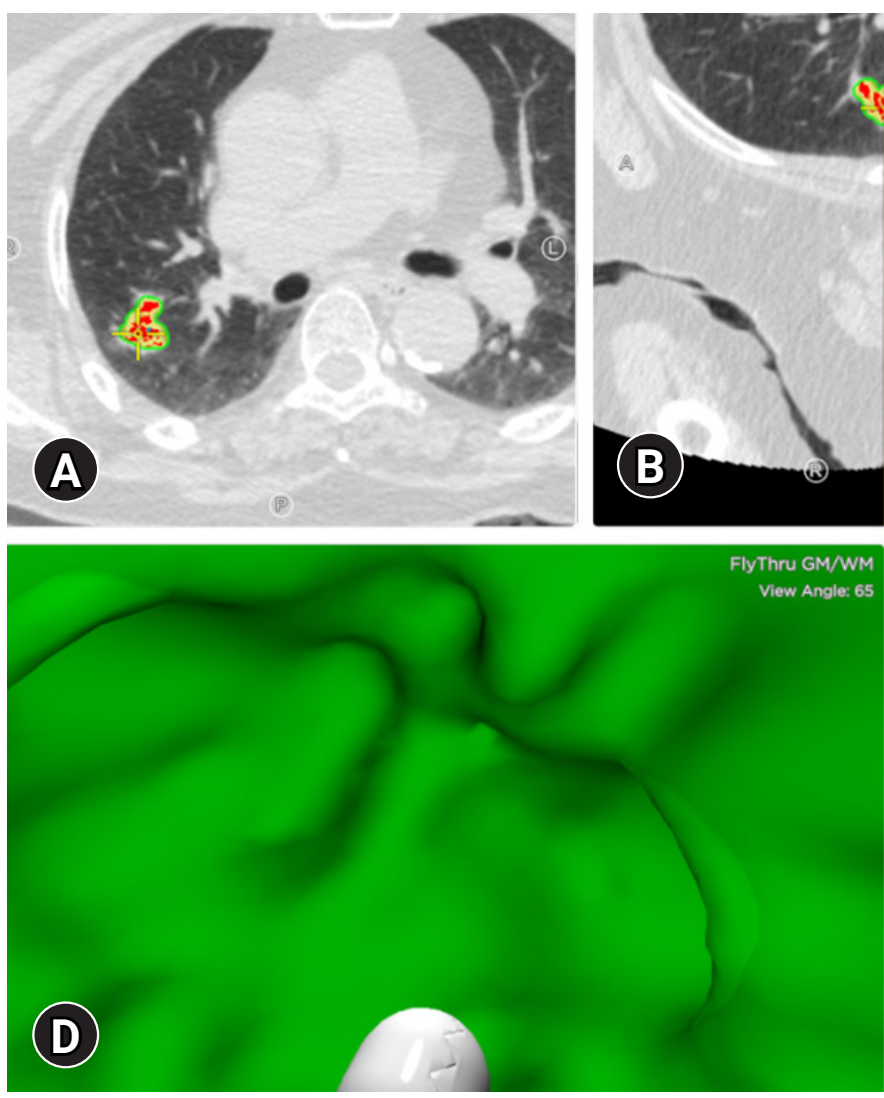
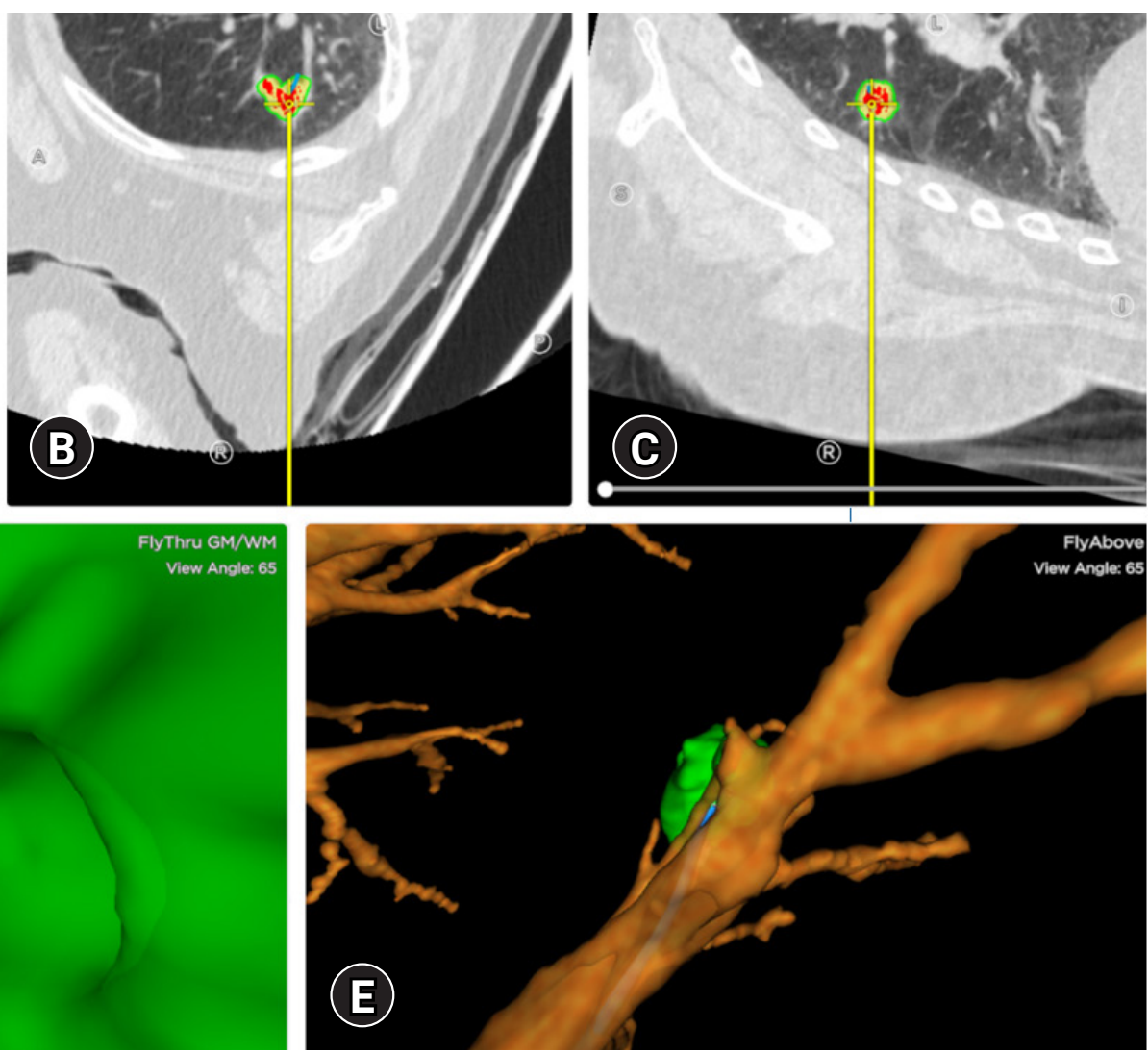

Fig. 5. (A-E) Electromagnetic navigational bronchoscopy assisted tissue sampling for a peripheral pulmonary lesion using the SPiN System (Veran Medical Technologies, St. Louis, MO, USA). 
ENB related complications such as pneumothorax, bleeding, and respiratory failure are reported in about $0 \%$ to $5 \%$ of the cases in several pieces of literature $[67,68]$. ENB can be an effective diagnostic method for cases undetectable by FB in high-risk patients with a low complication rate $[70]$.

\section{Cryobiopsy}

Transbronchial cryobiopsy is performed to obtain lung tissue for the diagnosis of interstitial lung diseases and lung tumors. Transbronchial cryobiopsy showed higher diagnostic yield than transbronchial forceps biopsy ( $91.67 \%$ vs. $73.13 \%, p=0.0002)$ in diagnosing interstitial lung diseases and lung tumors [71]. Meta-analysis revealed that the diagnostic yield ranged from $74 \%$ to $98 \%$, with a pooled estimate of $83 \%$ [72]. Quantitative assessment of samples showed that cryobiopsy samples were larger than forceps biopsy samples $\left(11.17 \mathrm{~mm}^{2}\right.$ vs. $\left.4.69 \mathrm{~mm}^{2}, p<0.001\right)$. A qualitative difference was not observed between cryobiopsy and forceps biopsy [73]. Pneumothorax (6.8\% to 12\%), moderate/severe bleeding (39\%), severe bleeding $(0.3 \%)$, and death $(0.1 \%)$ occurred after transbronchial cryobiopsy $[72,74]$.

\section{Conclusion}

In this review, we described the role of bronchoscopy in the diagnosis of pulmonary disease. The role of bronchoscopy in the diagnostic field is further increasing as more patients visit hospitals with chest imaging abnormalities due to the popularization of health check-ups. Recent developments in EBUS have enabled safer and more accurate examinations for diagnosing lung diseases. The development and combination of a variety of new diagnostic technologies, including ENB, is expected to make the diagnosis of difficult to diagnose lung diseases more feasible in the future.

\section{Acknowledgments}

\section{Conflicts of interest}

No potential conflict of interest relevant to this article was reported.

\section{ORCID}

June Hong Ahn, https://orcid.org/0000-0001-7104-8325

\section{References}

1. Panchabhai TS, Mehta AC. Historical perspectives of bronchoscopy: connecting the dots. Ann Am Thorac Soc 2015; 12:631-
41.

2. Silvestri GA, Gonzalez AV, Jantz MA, Margolis ML, Gould MK, Tanoue LT, et al. Methods for staging non-small cell lung cancer: diagnosis and management of lung cancer, 3rd ed: American College of Chest Physicians evidence-based clinical practice guidelines. Chest 2013; 143(5 Suppl):e211S-e250S.

3. Silvestri GA, Bevill BT, Huang J, Brooks M, Choi Y, Kennedy G, et al. An evaluation of diagnostic yield from bronchoscopy: the impact of clinical/radiographic factors, procedure type, and degree of suspicion for cancer. Chest 2020;157:1656-64.

4. Kurimoto N, Miyazawa T, Okimasa S, Maeda A, Oiwa H, Miyazu Y, et al. Endobronchial ultrasonography using a guide sheath increases the ability to diagnose peripheral pulmonary lesions endoscopically. Chest 2004;126:959-65.

5. Zhan P, Zhu QQ, Miu YY, Liu YF, Wang XX, Zhou ZJ, et al. Comparison between endobronchial ultrasound-guided transbronchial biopsy and CT-guided transthoracic lung biopsy for the diagnosis of peripheral lung cancer: a systematic review and meta-analysis. Transl Lung Cancer Res 2017;6:23-34.

6. Gupta AA, Sehgal IS, Dhooria S, Singh N, Aggarwal AN, Gupta $D$, et al. Indications for performing flexible bronchoscopy: trends over 34 years at a tertiary care hospital. Lung India 2015; 32:211-5.

7. Du Rand IA, Blaikley J, Booton R, Chaudhuri N, Gupta V, Khalid S, et al. British Thoracic Society guideline for diagnostic flexible bronchoscopy in adults: accredited by NICE. Thorax 2013;68(Suppl 1):i1-44.

8. Bai C, Huang H, Yao X, Zhu S, Li B, Hang J, et al. Application of flexible bronchoscopy in inhalation lung injury. Diagn Pathol 2013;8:174

9. Marek K, Piotr W, Stanisław S, Stefan G, Justyna G, Mariusz N, et al. Fibreoptic bronchoscopy in routine clinical practice in confirming the diagnosis and treatment of inhalation burns. Burns 2007;33:554-60.

10. Cha SI, Kim CH, Lee JH, Park JY, Jung TH, Choi WI, et al. Isolated smoke inhalation injuries: acute respiratory dysfunction, clinical outcomes, and short-term evolution of pulmonary functions with the effects of steroids. Burns 2007;33:200-8.

11. Cassada DC, Munyikwa MP, Moniz MP, Dieter RA Jr, Schuchmann GF, Enderson BL. Acute injuries of the trachea and major bronchi: importance of early diagnosis. Ann Thorac Surg 2000; 69:1563-7.

12. Chen CH, Lai CL, Tsai TT, Lee YC, Perng RP. Foreign body aspiration into the lower airway in Chinese adults. Chest 1997; 112:129-33.

13. Dikensoy O, Usalan C, Filiz A. Foreign body aspiration: clinical utility of flexible bronchoscopy. Postgrad Med J 2002; 78:399_ 
403.

14. Rivera MP, Mehta AC, Wahidi MM. Establishing the diagnosis of lung cancer: diagnosis and management of lung cancer, 3rd ed: American College of Chest Physicians evidence-based clinical practice guidelines. Chest 2013;143(5 Suppl):e142Se165S.

15. Shure D, Fedullo PF. Transbronchial needle aspiration in the diagnosis of submucosal and peribronchial bronchogenic carcinoma. Chest 1985;88:49-51.

16. Andersen HA, Fontana RS. Transbronchoscopic lung biopsy for diffuse pulmonary diseases: technique and results in 450 cases. Chest 1972;62:125-8.

17. Thomson CC, Duggal A, Bice T, Lederer DJ, Wilson KC, Raghu G. 2018 Clinical practice guideline summary for clinicians: diagnosis of idiopathic pulmonary fibrosis. Ann Am Thorac Soc 2019; 16:285-90.

18. Kebbe J, Abdo T. Interstitial lung disease: the diagnostic role of bronchoscopy. J Thorac Dis 2017;9(Suppl 10):S996-1010.

19. Sakr L, Dutau H. Massive hemoptysis: an update on the role of bronchoscopy in diagnosis and management. Respiration 2010;80:38-58.

20. Revel MP, Fournier LS, Hennebicque AS, Cuenod CA, Meyer G, Reynaud P, et al. Can CT replace bronchoscopy in the detection of the site and cause of bleeding in patients with large or massive hemoptysis? AJR Am J Roentgenol 2002;179:121724.

21. Khalil A, Soussan M, Mangiapan G, Fartoukh M, Parrot A, Carette MF. Utility of high-resolution chest CT scan in the emergency management of haemoptysis in the intensive care unit: severity, localization and aetiology. Br J Radiol 2007; $80: 21-5$.

22. Gagnon S, Quigley N, Dutau H, Delage A, Fortin M. Approach to hemoptysis in the modern era. Can Respir J 2017;2017: 1565030.

23. Pue CA, Pacht ER. Complications of fiberoptic bronchoscopy at a university hospital. Chest 1995;107:430-2.

24. Facciolongo N, Patelli M, Gasparini S, Lazzari Agli L, Salio M, Simonassi C, et al. Incidence of complications in bronchoscopy. Multicentre prospective study of 20,986 bronchoscopies. Monaldi Arch Chest Dis 2009;71:8-14.

25. Um SW. The role of EBUS-TBNA in the diagnosis and staging of lung cancer. Hanyang Med Rev 2014;34:20-5.

26. Yasufuku K, Chiyo M, Sekine Y, Chhajed PN, Shibuya K, Iizasa $\mathrm{T}$, et al. Real-time endobronchial ultrasound-guided transbronchial needle aspiration of mediastinal and hilar lymph nodes. Chest 2004; 126:122-8.

27. Hwangbo B, Lee HS, Lee GK, Lim KY, Lee SH, Kim HY, et al.
Transoesophageal needle aspiration using a convex probe ultrasonic bronchoscope. Respirology 2009;14:843-9.

28. Hwangbo B, Lee GK, Lee HS, Lim KY, Lee SH, Kim HY, et al. Transbronchial and transesophageal fine-needle aspiration using an ultrasound bronchoscope in mediastinal staging of potentially operable lung cancer. Chest 2010;138:795-802.

29. Lee R, Cousins DJ, Ortiz-Zapater E, Breen R, McLean E, Santis G. Gene expression profiling of endobronchial ultrasound (EBUS)-derived cytological fine needle aspirates from hilar and mediastinal lymph nodes in non-small cell lung cancer. Cytopathology 2013;24:351-5.

30. Schmid-Bindert G, Wang Y, Jiang H, Sun H, Henzler T, Wang $\mathrm{H}$, et al. EBUS-TBNA provides highest RNA yield for multiple biomarker testing from routinely obtained small biopsies in non-small cell lung cancer patients: a comparative study of three different minimal invasive sampling methods. PLoS One 2013;8:e77948.

31. Goag EK, Lee JM, Chung KS, Kim SY, Leem AY, Song JH, et al. Usefulness of bronchoscopic rebiopsy of non-small cell lung cancer with acquired resistance to epidermal growth factor receptor-tyrosine kinase inhibitor.J Cancer 2018;9:1113-20.

32. Izumo T, Matsumoto Y, Chavez C, Tsuchida T. Re-biopsy by endobronchial ultrasound procedures for mutation analysis of non-small cell lung cancer after EGFR tyrosine kinase inhibitor treatment. BMC Pulm Med 2016;16:106.

33. Lee HS, Lee GK, Lee HS, Kim MS, Lee JM, Kim HY, et al. Real-time endobronchial ultrasound-guided transbronchial needle aspiration in mediastinal staging of non-small cell lung cancer: how many aspirations per target lymph node station? Chest 2008; 134:368-74.

34. Wahidi MM, Herth F, Yasufuku K, Shepherd RW, Yarmus L, Chawla M, et al. Technical aspects of endobronchial ultrasound-guided transbronchial needle aspiration: CHEST guideline and expert panel report. Chest 2016;149:816-35.

35. Tournoy KG, Rintoul RC, van MeerbeeckJP, Carroll NR, Praet M, Buttery RC, et al. EBUS-TBNA for the diagnosis of central parenchymal lung lesions not visible at routine bronchoscopy. Lung Cancer 2009;63:45-9.

36. Nakajima T, Yasufuku K, Fujiwara T, Chiyo M, Sekine Y, Shibuya K, et al. Endobronchial ultrasound-guided transbronchial needle aspiration for the diagnosis of intrapulmonary lesions. J Thorac Oncol 2008;3:985-8.

37. Kuijvenhoven JC, Leoncini F, Crombag LC, Spijker R, Bonta PI, Korevaar DA, et al. Endobronchial ultrasound for the diagnosis of centrally located lung tumors: a systematic review and meta-analysis. Respiration 2020;99:441-50.

38. Labarca G, Sierra-Ruiz M, Kheir F, Folch E, Majid A, Mehta HJ, 
et al. Diagnostic accuracy of endobronchial ultrasound transbronchial needle aspiration in lymphoma: a systematic review and meta-analysis. Ann Am Thorac Soc 2019;16:1432-9.

39. Agarwal R, Srinivasan A, Aggarwal AN, Gupta D. Efficacy and safety of convex probe EBUS-TBNA in sarcoidosis: a systematic review and meta-analysis. Respir Med 2012;106:883-92.

40. Ye W, Zhang R, Xu X, Liu Y, Ying K. Diagnostic efficacy and safety of endobronchial ultrasound-guided transbronchial needle aspiration in intrathoracic tuberculosis: a meta-analysis. J Ultrasound Med 2015;34:1645-50.

41. Asano F, Aoe M, Ohsaki Y, Okada Y, Sasada S, Sato S, et al. Complications associated with endobronchial ultrasound-guided transbronchial needle aspiration: a nationwide survey by the Japan Society for Respiratory Endoscopy. Respir Res 2013; 14:50.

42. Dhooria S, Sehgal IS, Gupta N, Aggarwal AN, Behera D, Agarwal R. Diagnostic yield and complications of EBUS-TBNA performed under bronchoscopist-directed conscious sedation: single center experience of 1004 subjects. J Bronchology Interv Pulmonol 2017;24:7-14.

43. Caglayan B, Yilmaz A, Bilaceroglu S, Comert SS, Demirci NY, Salepci B. Complications of convex-probe endobronchial ultrasound-guided transbronchial needle aspiration: a multi-center retrospective study. Respir Care 2016;61:243-8.

44. Hurter T, Hanrath P. Endobronchial sonography: feasibility and preliminary results. Thorax 1992;47:565-7.

45. Kurimoto N, Murayama M, Yoshioka S, Nishisaka T. Analysis of the internal structure of peripheral pulmonary lesions using endobronchial ultrasonography. Chest 2002;122:1887-94.

46. Kikuchi E, Yamazaki K, Sukoh N, Kikuchi J, Asahina H, Imura $\mathrm{M}$, et al. Endobronchial ultrasonography with guide-sheath for peripheral pulmonary lesions. Eur Respir J 2004;24:533-7.

47. Chavez C, Sasada S, Izumo T, Watanabe J, Katsurada M, Matsumoto $\mathrm{Y}$, et al. Endobronchial ultrasound with a guide sheath for small malignant pulmonary nodules: a retrospective comparison between central and peripheral locations. J Thorac Dis 2015;7:596-602.

48. Tamiya M, Okamoto N, Sasada S, Shiroyama T, Morishita N, Suzuki H, et al. Diagnostic yield of combined bronchoscopy and endobronchial ultrasonography, under LungPoint guidance for small peripheral pulmonary lesions. Respirology 2013; 18:834-9.

49. Yamada N, Yamazaki K, Kurimoto N, Asahina H, Kikuchi E, Shinagawa N, et al. Factors related to diagnostic yield of transbronchial biopsy using endobronchial ultrasonography with a guide sheath in small peripheral pulmonary lesions. Chest 2007;132:603-8.
50. Moon SM, Choe J, Jeong BH, Um SW, Kim H, Kwon OJ, et al. Diagnostic performance of radial probe endobronchial ultrasound without a guide-sheath and the feasibility of molecular analysis. Tuberc Respir Dis (Seoul) 2019;82:319-27.

51. Yu KL, Tsai TH, Ho CC, Liao WY, Lin CK, Hsu CL, et al. The value of radial endobronchial ultrasound-guided bronchial brushing in peripheral non-squamous non-small cell lung cancer. Sci Rep 2018;8:5837.

52. Good WR, Christensen PM, Herath S, Dawkins P, Yap E. Radial-probe endobronchial ultrasound outcomes in the investigation of peripheral pulmonary lesions: a New Zealand perspective. Intern Med J 2018;48:1481-7.

53. Izumo T, Sasada S, Chavez C, Tsuchida T. The diagnostic utility of endobronchial ultrasonography with a guide sheath and tomosynthesis images for ground glass opacity pulmonary lesions. J Thorac Dis 2013;5:745-50.

54. Izumo T, Sasada S, Chavez C, Matsumoto Y, Tsuchida T. Radial endobronchial ultrasound images for ground-glass opacity pulmonary lesions. Eur Respir J 2015;45:1661-8.

55. Kim EJ, Kim KC. Utility of radial probe endobronchial ultrasound-guided transbronchial lung biopsy in diffuse lung lesions. Tuberc Respir Dis (Seoul) 2019;82:201-10.

56. Han Y, Kim HJ, Kong KA, Kim SJ, Lee SH, Ryu YJ, et al. Diagnosis of small pulmonary lesions by transbronchial lung biopsy with radial endobronchial ultrasound and virtual bronchoscopic navigation versus CT-guided transthoracic needle biopsy: a systematic review and meta-analysis. PLoS One 2018;13: e0191590.

57. Ahn JH, Jang JG. Initial experience in CT-guided percutaneous transthoracic needle biopsy of lung lesions performed by a pulmonologist. J Clin Med 2019;8:821.

58. Zhang L, Wu H, Wang G. Endobronchial ultrasonography using a guide sheath technique for diagnosis of peripheral pulmonary lesions. Endosc Ultrasound 2017;6:292-9.

59. Steinfort DP, Khor YH, Manser RL, Irving LB. Radial probe endobronchial ultrasound for the diagnosis of peripheral lung cancer: systematic review and meta-analysis. Eur Respir J 2011; 37:902-10.

60. Shinagawa N. A review of existing and new methods of bronchoscopic diagnosis of lung cancer. Respir Investig 2019;57:38.

61. Hasegawa S, Hitomi S, Murakawa M, Mori K. Development of an ultrathin fiberscope with a built-in channel for bronchoscopy in infants. Chest 1996;110:1543-6.

62. Oki M, Saka H, Kitagawa C, Tanaka S, Shimokata T, Mori K, et al. Novel thin bronchoscope with a $1.7-\mathrm{mm}$ working channel for peripheral pulmonary lesions. Eur Respir J 2008;32:465-71. 
63. Yamamoto S, Ueno K, Imamura F, Matsuoka H, Nagatomo I, Omiya Y, et al. Usefulness of ultrathin bronchoscopy in diagnosis of lung cancer. Lung Cancer 2004;46:43-8.

64. Oki M, Saka H, Ando M, Asano F, Kurimoto N, Morita K, et al. Ultrathin bronchoscopy with multimodal devices for peripheral pulmonary lesions: a randomized trial. Am J Respir Crit Care Med 2015;192:468-76.

65. Schwarz Y, Greif J, Becker HD, Ernst A, Mehta A. Real-time electromagnetic navigation bronchoscopy to peripheral lung lesions using overlaid CT images: the first human study. Chest 2006;129:988-94.

66. Dhillon SS, Harris K. Bronchoscopy for the diagnosis of peripheral lung lesions. J Thorac Dis 2017;9(Suppl 10):S1047-58.

67. Zhang W, Chen S, Dong X, Lei P. Meta-analysis of the diagnostic yield and safety of electromagnetic navigation bronchoscopy for lung nodules. J Thorac Dis 2015;7:799-809.

68. Folch EE, Pritchett MA, Nead MA, Bowling MR, Murgu SD, Krimsky WS, et al. Electromagnetic navigation bronchoscopy for peripheral pulmonary lesions: one-year results of the prospective, multicenter NAVIGATE study. J Thorac Oncol 2019; 14:445-58.

69. Eberhardt R, Anantham D, Ernst A, Feller-Kopman D, Herth F. Multimodality bronchoscopic diagnosis of peripheral lung le- sions: a randomized controlled trial. Am J Respir Crit Care Med 2007; 176:36-41.

70. Mahajan AK, Patel S, Hogarth DK, Wightman R. Electromagnetic navigational bronchoscopy: an effective and safe approach to diagnose peripheral lung lesions unreachable by conventional bronchoscopy in high-risk patients. J Bronchology Interv Pulmonol 2011;18:133-7.

71. Ganganah O, Guo SL, Chiniah M, Li YS. Efficacy and safety of cryobiopsy versus forceps biopsy for interstitial lung diseases and lung tumours: a systematic review and meta-analysis. Respirology 2016;21:834-41.

72. Johannson KA, Marcoux VS, Ronksley PE, Ryerson CJ. Diagnostic yield and complications of transbronchial lung cryobiopsy for interstitial lung disease: a systematic review and metaanalysis. Ann Am Thorac Soc 2016;13:1828-38.

73. Schuhmann M, Bostanci K, Bugalho A, Warth A, Schnabel PA, Herth FJ, et al. Endobronchial ultrasound-guided cryobiopsies in peripheral pulmonary lesions: a feasibility study. Eur Respir J 2014;43:233-9.

74. Dhooria S, Sehgal IS, Aggarwal AN, Behera D, Agarwal R. Diagnostic yield and safety of cryoprobe transbronchial lung biopsy in diffuse parenchymal lung diseases: systematic review and meta-analysis. Respir Care 2016;61:700-12. 